\title{
The Analysis of Platform Design for UAV Photography
}

\author{
Margarita Urbaha ${ }^{1}$, Vladimirs Petrovs ${ }^{2}$, Aleksandrs Jakovḷevs ${ }^{3}$, Kristine Carjova $^{4}$ \\ ${ }^{1-4}$ Institute of Aeronautics, Faculty of Transport an Mechanical Engineering, Riga Technical University
}

\begin{abstract}
Unmanned aerial vehicles (UAVs) are equipped with video surveillance devices (video cameras, photo cameras, infrared cameras, thermal imagers, etc.). Small aerial vehicles are most often equipped with stationary video cameras. However, for large-scale filming it is necessary to provide rotation of the camera in one or several planes. This article covers different opportunities to film objects or area irrespective of the AV flight path.
\end{abstract}

Keywords - Camera rotation mechanism, photography platform, unmanned aerial systems.

\section{INTRODUCTION}

The micro-class UAV should include an aerial vehicle capable of performing the following functions to ensure the universality of application:

- to carry out monitoring of objects;

- to perform tasks related to the protection and supervision of natural resources;

- to trace and report the location of objects being monitored;

- to carry out monitoring and predict the spread of forest fires;

- to carry out patrolling tasks and operations related to location and observation for the needs of the army and police;

- to map and monitor objects of national economy.

The design and circuit of the micro-class UAV should comply with the following characteristics:

- technical characteristics - UAV should be able to take off either by hand or from a catapult, carry out landing on a limited area and on an unprepared surface, provide the given flight range and duration, have durable and light construction with sufficient capacity, including load carrying capacity;

- efficiency of operation - UAV should be controlled in an automatic mode and carry out a flight along the given path with the possibility of switching to the manual or semiautomatic control mode;

- efficiency of maintenance - the system should be easy to maintain; replacement of parts and units should not be too complicated; the size and total weight of the system should be suitable for easy transportation; the aerial vehicle should be easy to disassemble.

The micro-class UAV has a number of controversial requirements for design and construction [1]. First of all, this is related to limitations to its takeoff weight and correspondingly to size. The vehicle of this class should be launched by hand or from a catapult, have sufficient flight duration and range as well as sufficient capacity, including load carrying capacity for placing disposable load. As a rule, it is most expedient to equip micro-class vehicles with an electric power plant - this is related to the ease of operation, reliability and ease of maintenance. However, in the given case the design of the aircraft should include a special compartment capacious enough for the power batteries that will provide the required time of operation of the engine and other systems. Owing to its small geometry and weight, the micro-class UAV during its operation is more subject to such environmental effects as, for example, wind gusts. In order to make it possible for the vehicle to carry the necessary disposable load, the airframe structure of the aircraft should be as light as possible and at the same time strong and stiff; the glider geometry should have as low aerodynamic drag as possible to reduce energy expenditure during cruising flight.

\section{SPECIFIC FEATURES OF MiCRO-CLASS UAV}

The design of micro-class UAV developed at the Institute of Aeronautics of Riga Technical University (Fig. 1) has several structural characteristics that ensure the compliance of the prototype with the above-mentioned parameters. The UAV fuselage has a shape that complies with the requirements of reduced aerodynamic drag and contains power batteries in a special compartment as well as control system and navigation elements. All disposable loads are placed in a special nacelle, which is hung at the bottom of the fuselage and has a shape providing reduced aerodynamic drag.

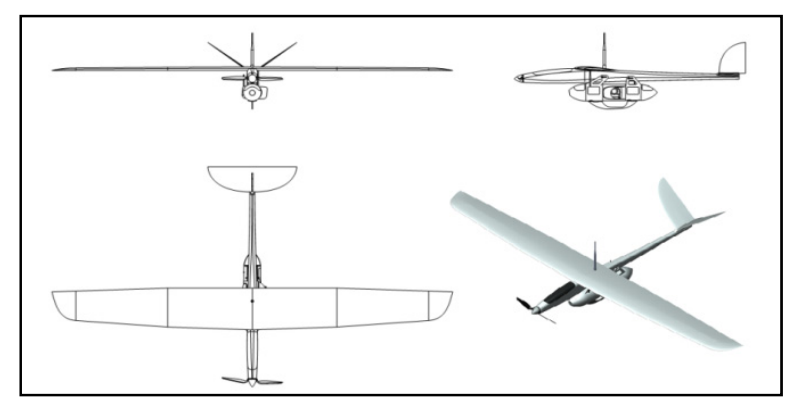

Fig. 1. Design layout of UAV.

The prototype of micro-class UAV has the following characteristics:

- construction weight $-2 \mathrm{~kg}$;

- $\quad$ flight duration - up to 1 hour;

- flight altitude - up to $3 \mathrm{~km}$;

- payload - up to $1.5 \mathrm{~kg}$; 
- engine type - electric.

The application of two independent cameras in one suspension system is one of the key features of the system. The navigation camera of the front view is intended for piloting the aerial vehicle. This is a fixed camera sending realtime images to the ground-based cockpit [2]. With the help of the navigation camera, it is possible not only to control the system but also to carry out monitoring and detect targets. The second camera - a high-resolution rotating camera placed in the suspension - is intended for photographing and video filming. If the system is controlled by one operator, it is possible to switch the AV to the automatic flight mode with the help of the navigation camera when the target is detected, for example, to circle with a certain radius while the operator uses the surveillance equipment to film/photograph the target [3], [4]. If the system is controlled by two operators, the efficiency of monitoring increases substantially. The UAV operator pilots the system in cooperation with an operator of photo and video equipment; thus, the area of observation is extended, and the speed of target detection and processing increases [5].

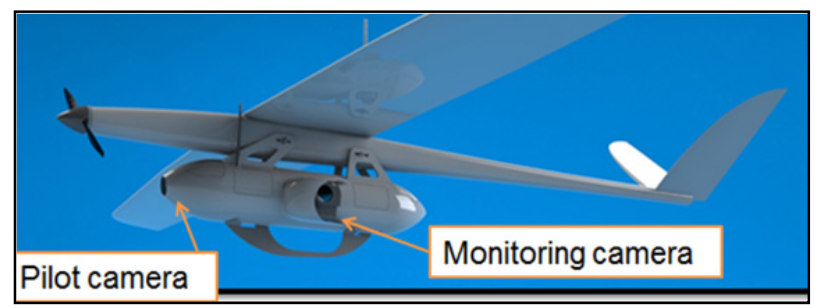

Fig. 2. UAV with its features.

The UAV has the following features:

- a special suspended nacelle for disposable load;

- a separate navigation camera for the system operator;

- a rotating high-resolution photo/video camera for monitoring (Fig. 2).

The micro-class UAV developed at the Institute of Aeronautics of Riga Technical University has a universal rotating platform inside the nacelle for disposable load and provides the opportunity to install photo and video equipment of different types (of suitable size and weight) to be fixed inside the nacelle. The prototype of the micro-class UAV can be equipped with [6]:

- video cameras;

- photo cameras;

- infrared camera;

- thermal camera;

- other devices.

\section{InVESTIGATION OF CAMERA Rotation MECHANiSM}

In order to create a camera rotation mechanism, a number of studies on the design and manufacturing of experimental samples were carried out.

The main objectives of the design were as follows:

- rotation of the platform with the camera around the lateral axis at an angle of $270^{\circ}-300^{\circ}$;
- providing unhampered access of wiring to the equipment in all compartments;

- providing optimum strength and weight characteristics for strength and fastening members;

- selecting an optimum servo drive and creating a rotation mechanism.

Optimum size and shape of the platform were chosen with account of overall dimensions of the equipment to be installed [7]. As the camera rotates along the lateral axis, the platform must correspondingly have a cylindrical shape. The platform can also rotate inside the cylindrical casing (skin). However, the choice was made in favour of the first variant because in this case the camera was better protected (Fig. 3).

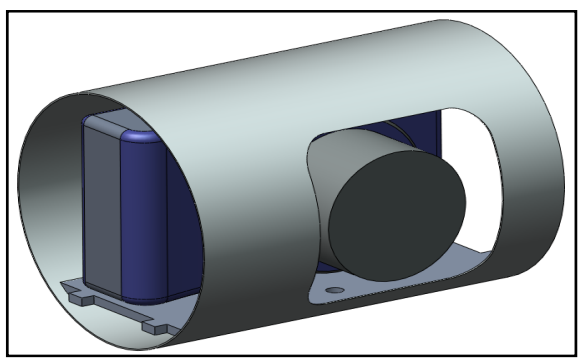

Fig. 3. Platform for the UAV camera.

To ensure unhampered rotation of the platform with the camera at an angle of $300^{\circ}$ on the condition that the wiring passes through load-bearing elements, it is necessary to place the wiring in the centre of rotating components [8]. Thus, the wires will be exposed to minimum deformation and will not hinder rotation. The load-bearing elements were optimized from the point of view of weight and strength.

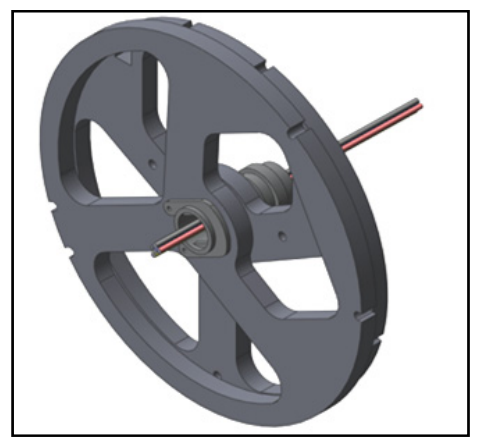

Fig. 4. Part of rotation mechanism.

Special attention was devoted to the creation of the mechanism itself. Rotation of such a structure cannot be implemented directly from the power drive because the rotation axis has a hole, where the wires are placed [9]. Therefore, it was necessary to design a reduction unit, which would transmit the drive from the servo drive with the help of gears [10]. Taking into account a limited rotation ability of the servo drive within the range of $120^{\circ}$, at the first stage it was decided to make a multiplier with a transmitting angle of $2: 1$ that would increase the angle of camera rotation up to $240^{\circ}$ [11]. Glass fibre plastic was chosen as the most suitable 
material for manufacturing gears and clamping frames from the point of view of strength and ease of processing.

When all the parts were manufactured, full-scale tests of the mechanism performance were carried out. Rotation was implemented at high turning speed with periodical sticking. The tests revealed the inadequate quality of manufacturing of parts and insufficient power of the servo drive that made it impossible to exceed the moment of the multiplier. It was unacceptable to use a more powerful servo drive because it would increase the weight of the whole structure; therefore it was decided to re-equip the servo drive by turning it into a constant rotation drive. The required result was achieved after the rearrangement of internal servo components.

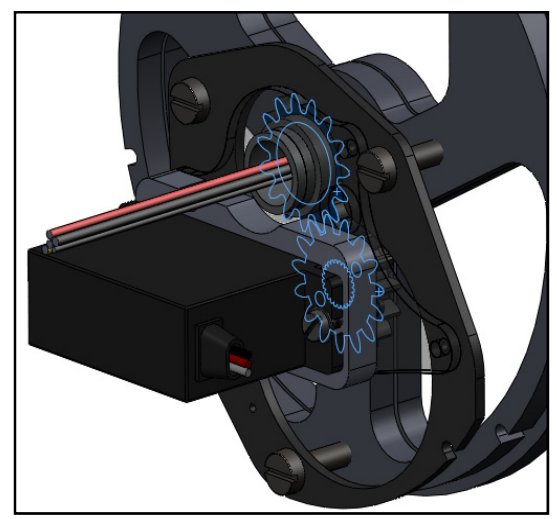

Fig. 5. Designing in SolidWorks.

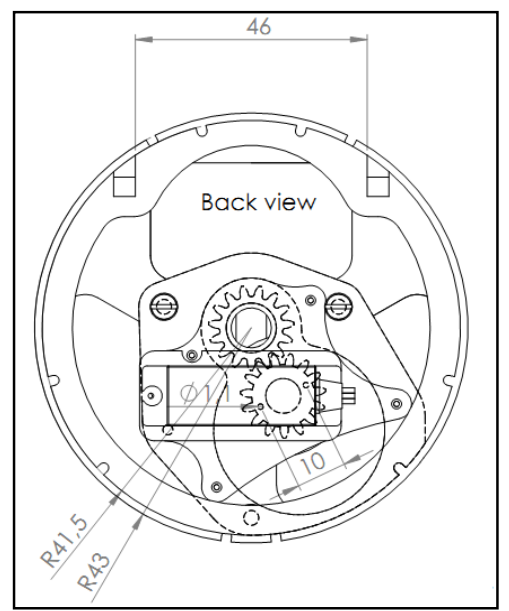

Fig. 6. Construction of rotating payload platform.

As a result, the multiplier was substituted with a reduction unit with 1:1 transmission, while the drive gear was reduced to the size of a driven gear. Gear manufacturing method was changed, which eliminated previous shortcomings of quality. In the end, rotation of the camera could occur perpetually but was limited only with the aim to prevent the twisting of wires (Fig. 4, Fig. 5, and Fig. 6). Thus, all the steps of the tasks were implemented.

\section{RESULTS}

The camera rotation mechanism has a constant rotation servo drive that makes it possible to rotate the camera at any angle [12]; the wiring of electronic devices passes through a special tube in the centre of the frame in order not to hinder the rotation of the middle part of the nacelle containing the surveillance equipment [13] (Fig. 7). External loads are transmitted to a special shaft and not directly to the servo drive, which provides the reliability of the structure.

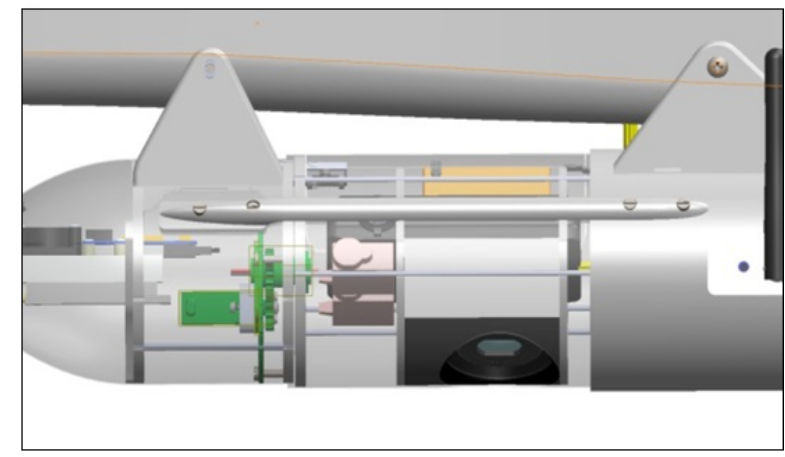

Fig. 7. Design of the nacelle rotation mechanism with disposable load.

The side high-resolution camera can turn at an angle of $230^{\circ}$ along the longitudinal axis. It gives the opportunity to film objects on both sides and directly below (Fig. 8) [14].
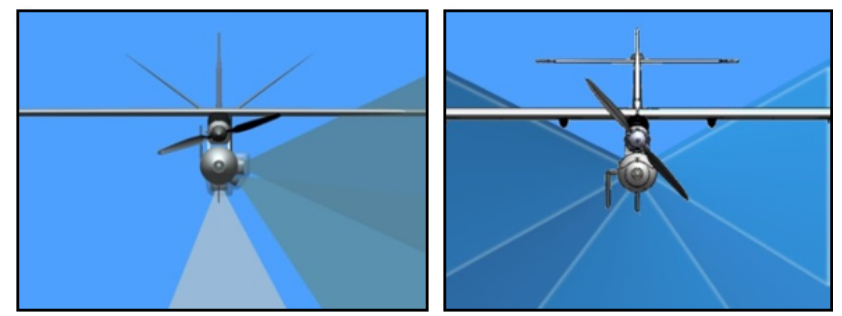

Fig. 8. Field of view of the side high-resolution camera.

The rotating part of the nacelle is also equipped with an independent stabilization system, which makes it possible to keep the camera at the right angle even when the aircraft is manoeuvring [15].

\section{CONCLUSIONS}

A detailed analysis of the design of the UAV has shown that it can be used for payload platform improvement. The use of non-standard design solution allows for the improvement of all parameters of the platform for UAV payload, such as field of view, control, weight and strength of the construction and ergonomics. 


\section{ACKNOWLEDGEMENTS}

\section{EIROPAS REGIONÄLĀS
ATTISTIBAS FONDS}

IEGULDĪJUMS TAVĀ NĀKOTNĒ

The research has been supported by the European Regional Development Fund within the framework of project "Development of an Unmanned Aircraft System and Creation of the Industrial Prototypes of Unmanned Aerial Vehicles for Performing the Tasks of Latvian National Economy" No.2010/0256/2DP/2.1.1.1.0/10/APIA/VIAA/070.

\section{REFERENCES}

[1] A. Urbahs, V. Petrovs, A. Jakovlevs and V. Bulanovs, Specificity of constructions and perspective of use and operations in transport systems UAS micro class: Proceedings of the International Conference Transport Means, October 21-22, pp. 202-206, Kaunas, Lietuva, 2011.

[2] A. Urbahs, M. Urbaha, V. Petrovs and A. Jakovlevs, Methods and means of the computer-aided design of unmanned aerial vehicle model: Proceeding of 2009 International Conference on Intelligent Engineering Systems (INES), pp. 211-213, Barbadosa, Barbados, 2009. http://dx.doi.org/10.1109/INES.2009.4924764

[3] M. Pivtoraiko, D. Mellinger and D. Kumar, Incremental micro-UAV motion replanning for exploring unknown environments: IEEE International Conference on Robotics and Automation, pp. 2452-2458, Karlsruhe, Germany, 2013.

[4] G. Guglieri, "Effect of autopilot modes on flight performances of electric mini-UAVs," Aeronautical Journal, vol. 117, pp. 57-59, 2013

[5] A.Urbahs, K. Savkovs, V. Bulanovs, V. Petrovs and A. Jakovlevs, Multipurpose unmanned aerial vehicle design: Proceedings of the International Conference Transport Means, October 23-24, pp. 30-32, Kaunas, Lietuva, 2008.

[6] A. Majka, "Flight loads of mini UAV," March 2013. [Online]. Available: http://www.scientific.net/ [Accessed Jan. 21, 2013].

[7] W. Zhang, N. Fan, Z. Wang and Y. Wu, Modelling and aerodynamic analysis of a ducted-fan micro aerial vehicle: Proceedings of 2012 International Conference on Modelling, Identification and Control ICMIC, pp. 768-773, June 24-26, Wuhan, Hubei, China, 2012.

[8] Y. Song, B. Xian, B. Ru and M. Cao, "Micro attitude and heading reference system for unmanned aerial vehicles," Journal of Central South University, pp. 91-93, 2013.

[9] K. J. Lemler and W. H. Semke, Application of modal testing and analysis techniques on a sUAV: Conference Proceedings of the Society for Experimental Mechanics Series, pp. 47-57, 2013.

[10] C. S. Chaney, A. Patrick, J. Leachma and K. Matveev, Development of the Genii-UAS demonstrator: A small-class vehicle with low wing loading and fuel cell propulsion: $31^{\text {st }}$ AIAA Applied Aerodynamics Conference 2013, pp. 2704-2717, San Diego, USA, 2013.

[11] A. Arena, G. Chowdhary, J. Conner, R. Gaeta, J, Jacob and J. Kidd, "Development of an Unmanned Aircraft Systems (UAS) option at the graduate level: $51^{\text {st }}$ AIAA Aerospace Sciences Meeting including the New Horizons Forum and Aerospace Exposition" January 2013. [Online]. Available: http://arc.aiaa.org/ [Accessed Jan. 21, 2013]

[12] D. Shetty and L. Manzione. Micro UAVs using mechatronics techniques: ASME International Mechanical Engineering Congress and Exposition, Proceedings (IMECE), pp. 565-574, 2012.

[13] N. A. Ahmed et al, "Manufacture of an unmanned aerial vehicle (UAV) for advanced project design using 3D printing technology," Applied Mechanics and Materials, pp. 397-400, 2013.

[14] V. Baiocchi, D. Dominici and M. Mormile, "Unmanned aerial vehicle for post seismic and other hazard scenarios." [Online]. Available: http://library.witpress.com/ [Accessed Jan. 21, 2013].

[15] J. U. Shin, D. Kim, J. H. Kim and H. Myung, Micro aerial vehicle type wall-climbing robot mechanism. IEEE International Workshop on Robot and Human Interactive Communication, pp. 722-725, August 26-29, Gyengju, China, 2013.

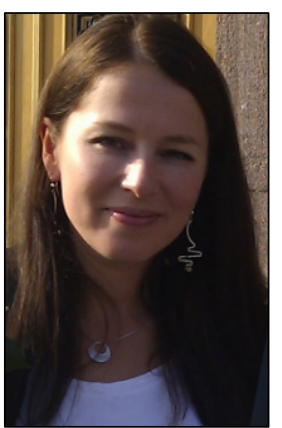

Margarita Urbaha graduated from the Faculty of Transport and Mechanical Engineering, Riga Technical University in 2011 and received the Dr.sc.ing. degree. Since 2012 she has been a Senior Researcher at the Institute of Aeronautics, Riga Technical University, and an Associate Professor at the Faculty of Transport and Mechanical Engineering, Riga Technical University. From 2010 to 2012 she was a Researcher at the Faculty of Transport and Mechanical Engineering, Riga Technical University. Since 2005 she has been a Project Manager at the Faculty of Transport and Mechanical Engineering, Riga Technical University. She is the author of 51 publications, 39 conference presentations. Her fields of research: aeronautics, unmanned vehicles, nano-composite coatings, non-destructive methods of control, transport systems and logistics. Address: Institute of Aeronautics, Faculty of Transport and Mechanical Engineering, Riga Technical University, Lomonosova 1A, k-1, Riga, LV1019, Latvia.

Phone: +371 67089990

E-mail: Margarita.Urbaha@rtu.lv

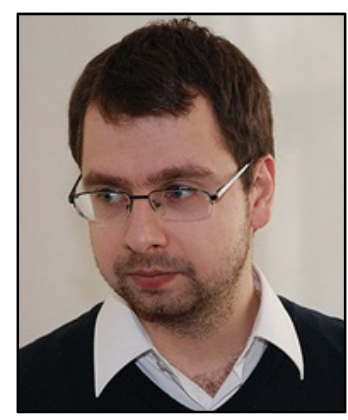

Vladimirs Petrovs received a degree of Master of Engineering Sciences from the Institute of Transport Vehicle Technologies, Faculty of Transport and Mechanical Engineering, Riga Technical University in 2009. In 2007 he received a Bachelor's Degree in Transport and Business Logistics from the Transport and Telecommunication Institute.

Work experience: Researcher at RTU, Institute of Aeronautics; Flight Operations Officer at LatCharter Airlines; SmartLynx Airlines, Flight Operations Department, ETOPS training, Crew Resource Management (CRM); Chief Designer of Unmanned Aerial Systems, Riga, Latvia.

Memberships in professional societies: Aircraft Owners and Pilot Association, AOPA; Air Safety Institute, a Division of the AOPA Foundation.

His fields of research: aeronautics, unmanned vehicles.

Address: Institute of Aeronautics, Faculty of Transport and Mechanical Engineering, Riga Technical University, Lomonosova 1A, k-1, Riga, LV1019, Latvia.

Phone: +371 67089990

E-mail: Vladimirs.Petrovs@rrtu.lv

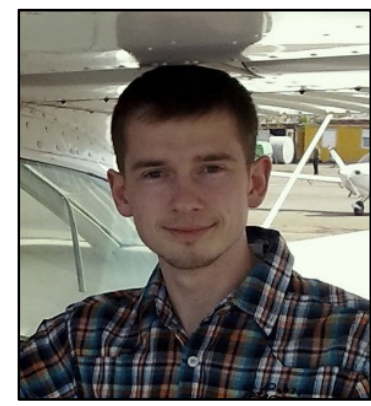

Aleksandrs Jakovḷevs received a degree of Master of Engineering Sciences from the Institute of Transport Vehicle Technologies, Faculty of Transport and Mechanical Engineering, Riga Technical University in 2011. In 2009 he received a Bachelor's Degree in Engineering of Transport Systems and a Qualification of Transport Engineer from RTU, Faculty of Transport and Mechanical Engineering, Institute of Transport Vehicle Technologies.

Work experience: Researcher at RTU, Institute of Aeronautics; Engineer of Transport Systems / Research Assistant, Principal Design Engineer of CAD / CAM / CAE, UAS Division (since 2008). His fields of research: aeronautics, unmanned vehicles.

Address: Institute of Aeronautics, Faculty of Transport and Mechanical Engineering, Riga Technical University, Lomonosova 1A, k-1, Riga, LV1019, Latvia.

Phone: +371 67089990

E-mail: Aleksandrs.Jakovlevs@rtu.lv 


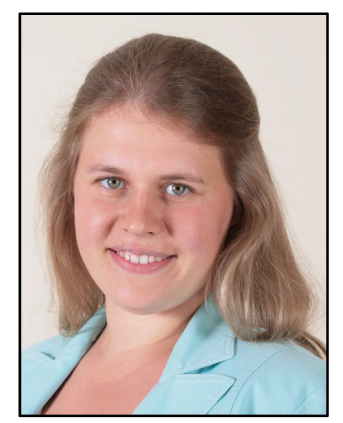

Kristine Carjova has been a Doctoral Student at the Institute of Aeronautics, Riga Technical University since 2011. In 2010 she obtained a degree of Master of Science at the Latvian Maritime Academy. She graduated from the Latvian Maritime Academy and obtained a Specialisation of Engineer-Ship Navigator. Work experience: 2004-2007 Navigator of Merchant Vessel; 2009-2011 Captain on ASD tugboat at JSC PKL Flote.
Since August 2011 - Researcher at the Institute of Aeronautics, Riga Technical University.

Her fields of research: aeronautics, nanomaterials, non-destructive methods of control, structural materials, unmanned vehicles, transport systems and logistics.

Address: Institute of Aeronautics, Faculty of Transport and Mechanical Engineering, Riga Technical University, Lomonosova 1A, k-1, Riga, LV1019, Latvia.

Phone: +371 67089990

E-mail: $\underline{\text { Kristine.Carjova@,rtu.lv }}$ 